\title{
Integrated Project Delivery Implementation Challenges in the Construction Industry
}

\author{
Zahra Kahvandi ${ }^{a}$, Ehsan Saghatforoush ${ }^{\text {b* }}$, Ahad ZareRavasan ${ }^{c}$, Christopher Preece ${ }^{\mathrm{d}}$ \\ ${ }^{a}$ M.Sc., Department of Project and Construction Management, MehrAlborz University (MAU), Tehran, Iran. \\ ${ }^{b}$ Senior Lecturer, School of Construction Economics and Management, University of the Witwatersrand, Johannesburg, South Africa. \\ ${ }^{c}$ Post-Doctoral Researcher, Department of Corporate Economy, Faculty of Economics and Administration, Masaryk University, Brno, Czech Republic. \\ ${ }^{d}$ Professor, Centre on Sustainable Built Environment, Abu Dhabi University, Abu Dhabi, United Arab Emirates.
}

Received 08 March 2019; Accepted 28 June 2019

\begin{abstract}
Huge financial resources are spent in the construction industry all over the world, which are frequently wasted largely due to a lack of proper planning. In recent decades, in an attempt to overcome challenges, various contractual and administrative systems have been used by construction owners/clients. One such system has been Integrated Project Delivery (IPD). Its implementation has, however, experienced drawbacks. Identifying such drawbacks is an initial step in attempting to resolve them, and this paper aims to identify and prioritize the IPD implementation drawbacks in the context of the Iranian construction industry. A comprehensive list of IPD implementation drawbacks is prepared using a questionnaire survey. An in-depth literature review of the IPD concept has been combined with a review of various case studies applying the IPD system. The results were analyzed using the Robust Exploratory Factor Analysis (EFA) method. 22 drawbacks in the Construction Industry were categorized under four themes; contractual, environmental, managerial, and technical. Results show that contractual drawbacks are the most significant. The implication of this research is that identifying and classifying IPD implementation drawbacks provides a useful reference to managers and owners of the construction industry, for identifying and codifying solutions to overcome them.
\end{abstract}

Keywords: Integrated Project Delivery (IPD); Challenges; Project Key Stakeholders; Construction; Robust Exploratory Factor Analysis (EFA).

\section{Introduction}

Demand for construction has been high, however, due to unsophisticated communications among its practitioners, it has been found to have very low efficiency [1]. The industry's owners should have a common language, to resolve management and communication problems, and to reduce inefficiency and confusion [2]. The construction industry has a great impact on the global economy and other industries; however, in the product delivery sector, information technology, and design, it suffers some challenges [3]. Given the huge volume of this industry, its changes have been so limited; so it has a low productivity. In this industry, billions of dollars are spent for project delays, duplication of work, changes, loss of materials, etc. [4]. In the United States, almost \$1 billion is spent on construction per year, and about $30 \%$ of this amount is wasted [5]. What is so significant in this regard, is financial success of the construction projects; however, the self-centered behavior of stakeholders under the traditional systems results in not achieving the desired outcomes $[6,7]$. On the other hand, funds of large projects are limited; therefore, the industry's owners attempt to attract

* Corresponding author: ehsan.saghatforoush@wits.ac.za

http://dx.doi.org/10.28991/cej-2019-03091362

(C) 2019 by the authors. Licensee C.E.J, Tehran, Iran. This article is an open access article distributed under the terms and conditions of the Creative Commons Attribution (CC-BY) license (http://creativecommons.org/licenses/by/4.0/). 
private sector investment. Consequently, maintaining this capital and careful planning for it is significant [8]. Project implementation method is a major factor in project success [9]. Project implementation is a process, in which a project is defined, designed, constructed, and maintained [10].

Integrated Project Delivery (IPD) is a project implementation approach, which creates directions for change to improve contracts, to make planning more precise, to make cooperation more productive, to make communications more effective, and generally to eliminate lag of the construction industry relative to other sectors [2]. This approach uses a participatory method; therefore project objectives are realized more effectively [11]. The Architectural Institute of America (AIA) defines IPD as: "it is a project implementation system that benefits from talents and constructive cooperation and experiences of all project stakeholders, through using a multilateral contract in an integrated way, to achieve success [12]. In fact, IPD is a philosophy, an intellectual attitude. Stakeholders share their information and resources to meet their obligations [13].

The IPD approach includes the following principles: mutual trust and respect, which are based on teamwork and team building. Common profit and loss, according to the terms of presence of each of stakeholders in the project, their profit and loss will be based on an agreement. Free communications are defined properly as a result of responsibilities, and conflicts among the members are minimized. Early introduction of target leads to strengthening incentives. Leadership is assigned to a qualified person. Strengthening planning, this results in correct timing and better control of costs. Creativity in decision-making, which is due to free exchange of views. Early involvement in the project, which leads to a better sharing of experiences. Appropriate technology, which is considered as one of the significant factors of IPD implementation [12]. Applying these principles leads to removing borders existed in the traditional contracts. Therefore, objectives and responsibilities are defined more clearly [14]. Now, IPD approach is not used widely [15]. However, according to the studies conducted by El Asmar et.al. In the field of comparing traditional methods and IPD, it is hoped using IPD in future is growing, because increasing product quality follows proper environmental and financial performance, reducing project changes, etc. [6].

Identifying and reviewing challenges and introducing solutions to resolve them, will be a useful step toward IPD implementation. In the research conducted by Kahvandi et al. [16], some IPD challenges were identified as macro factors, such as capital factors, organizational factors, and environmental factors, through examining researches conducted during 2001 and 2016. These factors include several challenges. Finally, 44 items obtained through metasynthesis approach, which is used in this study.

The necessity of research is important considering the two factors "time" and "place ". Time was important in this research because the developments in the construction industry are happening quickly and costs are rising. The place is also important because developing countries are looking for solutions to the advancement of the construction industry. This paper aims to evaluate IPD implementation challenges in the construction industry in the mass-housing projects. Using IPD challenges evaluation and classification, more significant challenges can be identified. Comprehensive and accurate planning can be effective in coping with these challenges, and it will help enhancing knowledge integration [6, 17]. Consequently, it leads to massive savings in products and improving their quality, which results in enhancing life quality. Moreover, it will lead to increased energy management capabilities, increased safety, increased productivity, and sustained environment $[18,19]$. The next section examines research background.

\section{Literature Review}

In this section, the definitions related to IPD are reviewed, also the importance of considering IPD implementation challenges are illustrated.

\subsection{Integrated Project Delivery (IPD)}

During recent years, the Construction Industry has seen significant progress in implementing project implementation systems. These advances have been the implementation of the IPD approach which may help to solve many age-old problems. The necessity to increase productivity in the Construction Industry, stakeholders' demands, market needs, increasing complexity of technology in the Construction Industry, and the need for buildings' stability, are some of the features that justify the necessity of applying IPD [2, 20]. In the process of implementing a project, employer, consultant, main contractor, sub-contractors, suppliers, and manufacturers play significant roles together [9]. Various organizations are also considered as key stakeholders of a project. An important step in continuing the work is establishing effective relations among these stakeholders. In the traditional systems, due to the restrictions imposed by contracts, these relations have various limitations, particularly for the construction contractors with designers, and with maintenance contractors, which leads to developing conflicts [3]. With the help of IPD that creates trust and clarity in relations, and makes the stakeholders participate in the initial phases of the project, these conflicts may be reduced [21].

The IPD approach has several advantages, some of which are defined by Collins and Parrish 2014 and the Architectural Institute of America (AIA 2007) [22], and some others are classified in the implementation section in the 
reviewed case studies [21]. Some of these advantages are increased accuracy of project control, increased product quality, reduced construction time, better leadership, etc., which are the most significant factors for project employers/clients [23]. Reducing costs, accurate planning, participation in profits, etc. are of considerable importance for contractors [8]. Items such as reducing claims, reducing waste of resources, reducing wastes and others are also common between the contractor and the employer [24]. However, what is important for designers is designing in line with the needs of the employer and improving design quality [4]. Due to the presence of the contractor in the initial stages of the project, reducing change orders and reducing the request for information are in favor by the contractor [11], [12]. Finally, advantages such as public decision-making, developing long-term relations among stakeholders, the possibility of using integrated software, and others are also common among the employer, contractor, and designer [25].

The Architectural Institute of America (AIA) has developed various contract forms to implement IPD [26]. What is so significant in these multilateral standard contracts, is the high rate of agreement among the stakeholders [27]. Typically, in IPD, there is a contract for the entire project, and it includes all of the project stakeholders. In this regard, cooperation and coordination for the entire project are improved significantly [28].

\subsection{IPD Implementation Challenges}

What is significant is that evaluating IPD advantages alone is not sufficient for its effective implementation [29]. Researchers have evaluated various aspects of its implementation. Numerous studies have examined IPD implementation challenges considering the conditions of different regions of the world and their governing rules on the Construction Industry. Kent et al., through examining the attitude of experienced experts in the Construction Industry, have concluded that they are optimistic about IPD implementation and its consequences. However, advanced information and technological applications are prerequisites for IPD implementation [19, 30]; so supplying it, requires many possibilities. On the other hand, cultural challenges and organizational resistance to changing their previous trends are among other factors mentioned by Kent et al. (2010) [31, 32]. Resolving these challenges by stakeholders provides significant results of IPD implementation. For example, in a medical center project in San Francisco, implementing IPD saved about $\$ 1$ million in the electrical equipment sector and about \$5 million in the mechanical sector. In the medical center building in Fairfield, the initial budget was estimated at $\$ 12$ million, which was reduced to $\$ 19$ million by applying IPD. In both projects, by agreement of the employer, the contractors of the maintenance section were presented in the initial stages of the project as a consultant [25]. Another example is Cathedral Hill Hospital in the United States. In this project, there was the problem of determining final costs, which was completed at the right cost, by using IPD contract and entrance of contractors with the responsibility of supplying resources and equipment [21, 33].

During studies performed Ghassemi and Greber (2011), IPD implementation challenges were divided into four main categories, including cultural; these challenges refer to the reluctance of industry's owners to change the traditional methods $[26,34,35]$. Changing their attitude needs a hierarchical because the construction companies have accustomed to their limited leadership [27]. Financial challenges; selecting compensation for damages is a big challenge in IPD implementation $[21,26]$. Legal challenges; issues related to responsibility and insurance are among other challenges of IPD implementation. Current insurances don't fully support delegating responsibility [21, 26, 36]. Technology, cooperation, and integrated use of technology in IPD implementation are considered as significant steps in its implementation. Training at organizational levels is also very important in resolving cultural challenges [31, 37].

Manning in the study conducted in 2012concluded that the necessity of IPD implementation is applying advanced technology in the architectural and engineering aspects of construction [8, 23]. Employer liability insurance with special conditions is also significant because if insurance companies don't support IPD, sharing profit and loss will not be implementable. Another challenge in this regard is lack of training and introducing IPD to employees [8, 12]. According to the conducted studies by Nejati et al. (2014), IPD implementation challenges in the mass housing projects include: distrust of stakeholders to each other, the right of final decision-making about particular issues just for the employer, high levels of discretion of the employer, lack of familiarity with BIM, unwillingness to use new methods in implementing contracts, lack of financial transparency, unwillingness of the employer to share project profit with the consultant, lack of special plan for profit and loss, lack of transparency in the costs of contractors, unwillingness of the contractor to participate in the design stage, lack of knowledgeable people to resolve claims and lack of sufficient knowledge about developing an industrial method among consultants [14, 38, 39].

Evaluating challenges was also conducted by Kahvandi et al. (2019) IPD challenges included macro factors such as capital, organizational, and environmental factors. Capital factors include financial challenges; and organizational factors include managerial, contractual, educational, communication, and technology challenges. Environmental factors included cultural, legal, and political challenges. Finally, 44 codes were obtained using meta-synthesis approach [16].

In this study, these 44 codes were analyzed.The significance of this study is for rooting IPD challenges, and to highlight them for decision-makers to be able to resolve them more effectively. Resolving challenges will pave the road for better IPD implementation [16, 40]. The next section introduces the research method. 


\section{Research Methodology}

The research steps are shown in Figure 1. In Appendix I, a 44-item questionnaire is presented based on the literature review and investigated IPD projects' challenges. The survey instrument asked the respondents to rate the importance of every 44 challenges using a nine-point scale with items ranged from 1 (strongly low) to 9 (strongly high). In this research, activists in the field of construction in Iran with experience using IPD and project managers and employers and consultants and contractors with a high academic level and more than five years of experience participated.

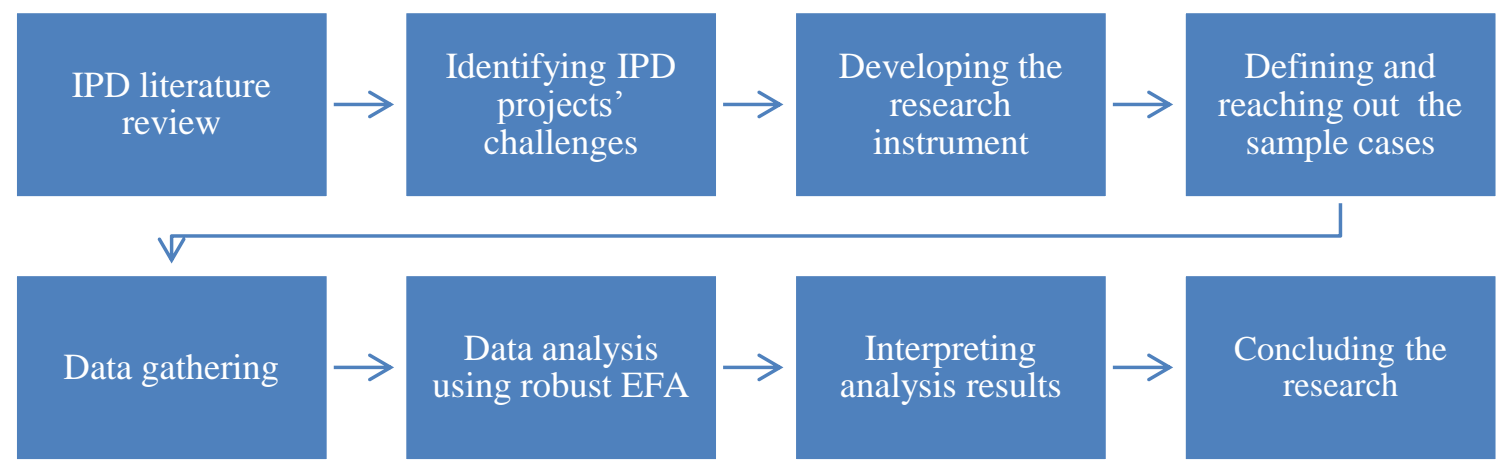

Figure 1. The research steps

To gather data from the respondents, first, the companies and related experts were identified. They were asked to fill the questionnaire and finally, they completed the questionnaires (Appendix I). In total, 500 questionnaires were sent out to the respondents, 245 questionnaires were gathered, and 225 usable questionnaires were included in the data analysis (response rate: 0.45 ). The sample size of 225 seems to be adequate for conducting robust EFA (recommended ratio of 5:1) [41].

EFA is used in this study which is a frequently used method to discover patterns of multidimensional constructs that are subsequently used for the development of measurement scales. Its principal objective is to reduce the number of observed variables to fewer factors to enhance interpretability and detect hidden structures in the data. In other words, EFA's purpose is to ascertain the most parsimonious number of interpretable factors required to explain the correlations among the observed variables, with or without underlying theoretical processes in mind. Thus, EFA is a method for identifying the factor structure of a set of multiple indicators or variables without imposing an a priori structure on the factors. EFA is performed at early stages of research to consolidate variables and generate new hypotheses about underlying theoretical processes [42]. Here, robust EFA [43] was employed to perform the analysis which is less influenced by data outliers and data heterogeneities.

\section{Results}

Before conducting robust EFA analysis, a test was conducted to verify the adequacy of the data. The Kaiser-MeyerOlkin (KMO) was calculated to ensure sampling adequacy. The KMO for the sample is 0.75 which is above the "Mediocre" threshold of 0.5 [43]. Furthermore, the authors performed a Bartlett sphericity test, which was statistically significant $(\mathrm{p}<0.05)$, indicating the eligibility of the data. Then, we used a Shapiro-Wilk test to determine whether the sample had a normal distribution. It was found that none of the variables were normally distributed. Thus, principal component analysis (PCA) was the choice for the factor extraction method as proposed in robust EFA. The rotation method should also be selected for the robust EFA purpose. Oblimin rotation, which is suggested in robust EFA was used in this research [43]. Finally, the number of factors to be extracted from the data were determined based on Eigen values greater than one, and an absolute factor loading values greater than 0.6 [44]. As a result, two out of 22 factors were dropped from the initial pool and remained 22 factors were grouped into four components. The results can be seen from Table 1.

Table 1. The results of robust EFA

\begin{tabular}{lcc}
\hline \multicolumn{1}{c}{ Items } & $\mathbf{1}$ & $\mathbf{2}$ \\
\hline 1. Lack of mutual trust among project key stakeholders regarding managerial and financial issues & 0.90 & 0.83 \\
2. Lack of appropriate policies and current construction contractual strategies & 0.72 \\
3. Lack of identical contracts among subcontractors, such as IPD approach & 0.81 \\
4. Tendency to use conventional contractual methods and resistance to new ideas & 0.89 \\
5. Lack of proper definition of responsibilities of each of parties of the contract & 0.74 \\
6. Lack of motivation for investors to use modern contracts, such as IPD approach & 0.81 \\
7. Lack of control and strong management of the employer & \\
\hline
\end{tabular}


8. Lack of proper orientation for future and not paying attention to future development, particularly in the governmental projects

9. Lack of familiarity of contractors with IPD approach

10. Lack of conditions for the insurance to cover the entire project in the country, according to new contractual systems

11. Lack of conditions for the insurance to cover the responsibilities according to new contractual systems for the contractor

12. Non-participation of governmental agencies in construction, according to the governing rules in the governmental contracts

13. The challenge of selecting compensator for financial losses

14. Inconsistency in project management

15. Poor matrix structure in project-based organizations

16. Lack of sufficient knowledge of investors about new successful contractual systems all over the world

17. Lack of holding training courses for investors about defining and stating the advantages of new successful contractual systems all over the world

18. Poor information sharing among different phases of the project

19. Lack of proper definition of teamwork culture among project key stakeholders

20. Lack of integrated collaboration among key stakeholders, due to lack of the necessary technology

21. Lack of using BIM as an appropriate instrument to implement IPD approach agents

\begin{tabular}{|c|c|c|c|c|}
\hline$\%$ of variance & 23.94 & 20.04 & 16.12 & 12.45 \\
\hline Cumulative \% & & 43.98 & 60.1 & 72.55 \\
\hline
\end{tabular}

Extraction method used is Principle Component Analysis and the rotation method used is obliging.

To indicate the meaning of the components, they have been given short labels indicating their content. Since the results of this stage were open to several interpretations, the authors decided to use experts' opinions. Consequently three IPD project managers were selected, who had the experience of using IPD with high academic level and more than five years of experience. Based on the discussions on the factors' meanings in each component, four "Managerial", "Environmental", "Contractual", and finally "Technical" labels were assigned to the extracted components. The final results are shown in Table 2.

Table 2. Extracted components and their related factors

\begin{tabular}{|c|c|}
\hline Components' Title & Factors' title \\
\hline \multirow{7}{*}{ Managerial } & The challenge of selecting compensator for financial losses \\
\hline & Inconsistency in project management \\
\hline & Poor matrix structure in project-based organizations \\
\hline & Lack of sufficient knowledge of investors about new successful contractual systems all over the world \\
\hline & $\begin{array}{l}\text { Lack of holding training courses for investors about defining and stating the advantages of new successful contractual } \\
\text { systems all over the world }\end{array}$ \\
\hline & Poor information sharing among different phases of the project \\
\hline & Lack of proper definition of teamwork culture among project key stakeholders \\
\hline \multirow{7}{*}{ Environmental } & Lack of motivation for investors to use modern contracts, such as IPD approach \\
\hline & Lack of control and strong management of the employer \\
\hline & $\begin{array}{l}\text { Lack of proper orientation for future and not paying attention to future development, particularly in the governmental } \\
\text { projects }\end{array}$ \\
\hline & Lack of familiarity of contractors with IPD approach \\
\hline & Lack of conditions for the insurance to cover the entire project in the country, according to new contractual systems \\
\hline & $\begin{array}{l}\text { Lack of conditions for the insurance to cover the responsibilities according to new contractual systems for the } \\
\text { contractor }\end{array}$ \\
\hline & $\begin{array}{l}\text { Non-participation of governmental agencies in construction, according to the governing rules in the governmental } \\
\text { contracts }\end{array}$ \\
\hline \multirow{5}{*}{ Contractual } & Lack of mutual trust among project key stakeholders regarding managerial and financial issues \\
\hline & Lack of appropriate policies and current construction contractual strategies \\
\hline & Lack of identical contracts among subcontractors, such as IPD approach \\
\hline & Tendency to use conventional contractual methods and resistance to new ideas \\
\hline & Lack of proper definition of responsibilities of each of parties of the contract \\
\hline
\end{tabular}




\section{Discussion}

Information classification has advantages even at the level of global investment. It also influences the level of accessibility to minimize the effects of risks. The classification of data in each section is part of the needs of each system. In previous studies, there were categories for challenges to IPD implementation but in this research, the authors have tried to make the categorization more fully with the new methodology. According to the percent of variance mentioned in Table 1, the order of factors is: 1) contractual, 2) environmental, 3) managerial, and finally 4) technical.

According to what is achieved in this classification, contractual challenges with $23.94 \%$ of explained variance are the most significant challenges. This is due to the fact that the IPD system at first includes a contractual system that includes the project lifecycle [12]. Consequently, contractual challenges cause problems in IPD implementation due to various factors. Mutual trust in contracts, particularly in the IPD system, is one of the conditions for its success. According to the behavioral and communicative principles in IPD, i.e., the culture of mutual respect and cooperation and participation and transparent relations and open communication, etc. trust and IPD should cooperate with each other [45]. In a medical project in Denver, with 430,000 SF area and \$160 million costs, and 24 months timing, the IPD approach was performed successfully and reduced costs by $26 \%$ relative to similar contracts such as Design-Bid-Build (DBB) with 13\% cost reduction, and Design-Build (DB) and Construction Management at Risk (CMR) with 17\% cost reduction [32]. In another project in Phoenix, United States, Walter Cronkite School of Journalism, there was state law prohibits for IPD implementation. Therefore, design and construction contract was used with respecting behavioral principles and some IPD contractual principles. Finally, the project was completed without wasting money [25].

In each project, two sets of factors are effective; one set of internal and intra-organizational factors, which here are referred to as managerial factors; and another set of external and environmental factors. Environmental factors (the second most important category with $20.04 \%$ of variance) are largely influenced by state laws and cultural factors [14]. Reforming state laws to implement IPD, is very significant. In a project in the United States, project contract was signed using design and construction, due to State challenges. In this contract, two main factors of IPD were used; i.e., the participation of key stakeholders from the beginning of the project and their joint decision-making and supervision [26]. Issues related to insurance and rules related to compensating losses are significant in projects.

In IPD, conflicts will be minimized, by reducing some of the authorities and increasing cooperation. Current insurance contracts have some terms that make responsibilities more complicated; consequently, stakeholders' authorities for IPD implementation are not specified explicitly [46]. Therefore, in recent years, no IPD particular insurance contract has been developed, IPD users have to change the way of using insurance. For example, the Autodesk One Market project in the United States was performed in a building with 40,000 SF areas and about \$10 million budget and 9.5 months planning. The project team used insurance contracts, with this difference that all of the claims were deleted by the agreement of all stakeholders, except items related to fraud and neglect in the job [26]. The Proper definition of IPD and introducing its advantages will be effective to attract the attention of insurance companies and banks to compensate financial losses. In some projects, resolving the challenge of the unfamiliarity of contractors with IPD approach has had significant consequences. For example, in the Cardinal Glennon Children's Hospital project in the United States, holding training courses convinced stakeholders to use an integrated contract to overcome the problem of lack of flexibility of traditional contracts and reducing project's complexities [25].

The results of this study show that managerial category is the third most important set of challenges. Lack of coordination in selecting the compensator of financial losses is one of the challenges that violates IPD principles, because in IPD, a high level of coordination and cooperation in all units is required, and profit and loss are divided jointly among the stakeholders [47]. On the other hand, a part of the managerial challenges is related to intra-organizational issues, which are solvable by basic changes in the structure of project-based organizations and creating coordination and proper determination of duties. The training sector is one of the most important sectors that started to use new systems. Developing this sector can be helped with real examples of successful IPD implementation in other projects [12]. These challenges are rooted in the traditional systems of project implementation; because in such systems, relations are so limited and after the completion, each project's phase is given to other stakeholders. Therefore, cooperation and coordination among stakeholders were very low [26]. On the other hand, it can be stated that resolving managerial challenges, due to their significance, provides a clear vision for solving other challenges.

Using technology, in any industry can be challenging. In IPD, information integration needs to resolve the challenges [11]. Building Information Modeling (BIM) is an instrument required for information integration capability in IPD. However, lack of sufficient knowledge and lack of applying it in the country has been shown to make IPD implementation challenging. In similar projects using IPD, such as Autodesk One Market in the United States, 
cooperation between BIM and MEP made the maintenance sub-contractors to enter the design stage and save the costs and time significantly [26]. In fact, BIM creates a platform to share information and is very effective in the field of responsibilities and ownership of activities [48]. In some projects, time and costs were saved significantly [26].

The classification obtained in this study is largely in line with the results achieved from the previous studies [14], [26]. Because of these macro factors, besides their various impacts on the construction industry, are the concerns of many owners of this industry and is common among all of them. Consequently, classifying macro factors is significant, because it defines a useful database, which can be effective for planning and resolving the challenges and reducing negative effects $[46,49]$. On the other hand, it can be stated that in this study a summary of significant items has been determined and updated, to be available. The classified macro factors include many subsets in the construction industry, all of which are effective factors in this Industry. Considering the large investment in IPD, the smallest changes in each of them, could result in significant savings in time and cost in the construction. In this paper, problems were identified with the study of library studies and the question of project stakeholders. These items were ranked by a comprehensive survey, to determine the most significant items. Identifying these items and evaluating them, provides this possibility for industry's owners to try to resolve them, to implement IPD in the best way.

\section{Conclusion}

In this study, a comprehensive list of challenges to apply IPD was developed in the form of a questionnaire, through use of a comprehensive literature review and examination of case studies using IPD. This was followed by a survey of project managers and employers and consultants and contractors active in the field of construction. The obtained results were analyzed using the Exploratory Factor Analysis method. Among 44 questioned items, 22 items of IPD implementation challenges in the construction industry were prioritized. Then, they were classified by some experts of the Industry, into four categories or macro factors including contractual, environmental, managerial, and technical ones. These were analyzed in the previous section. The results showed that contractual macro factors are considered as IPD implementation challenges in the Iranian construction sector. What was significant in this study was that resolving contractual challenges is very effective in resolving environmental, managerial, and technical challenges. What is significant is that IPD successful implementation requires resolving basic challenges and resolving those challenges faced during its implementation. The conditions of projects are unique; so considering its situation, there are different and similar solutions to resolve them. However, what is obtained from the experiences of recent years about IPD implementation is its' significant success is saving time and costs in the project lifecycle. Classifying these challenges can be used by industry's owners to help resolve them.

The main limitation of the study was the lack of case studies using a multi-party IPD contract. There were also IPD projects that were currently under construction which further reduced the sample size of IPD projects. For future studies, these classified challenges can be evaluated through case studies implemented by IPD and countries such as the United States, Australia, Canada, and others that implement IPD contracts, or various solutions can be presented for resolving them by surveying experts. By examining more case studies, other potential challenges of projects can be analyzed that are developed due to their special conditions. Moreover, future research can move beyond listing challenges and could explore the interrelationships between them.

\section{Conflicts of Interest}

The authors declare no conflict of interest.

\section{References}

[1] Shahhosseini, V., E. Shakeri, H. Hajarolasvadi, and A. N. Naderi. "Integrated Project Delivery, A New Approach in Management and Implementation of Civil Projects." In 9th Internationl Project Management Conference, pp. 1-13. 2014.

[2] Sive, Ted. "Integrated project delivery: Reality and promise, a strategist's guide to understanding and marketing IPD." Society for Marketing Professional Services Foundation (2009).

[3] Lee, Hyun Woo, Iris D. Tommelein, and Glenn Ballard. "Energy-Related Risk Management in Integrated Project Delivery." Journal of Construction Engineering and Management 139, no. 12 (December 2013): A4013001. doi:10.1061/(asce)co.19437862.0000753 .

[4] Hassan, Mohamed E. "Assessing the impact of lean/integrated project delivery system on final project success." PhD diss., 2013.

[5] Bryson, B, and Yetmen. “The Owner's Dilemma.” Atlanta, Gorgia: Greenway Communication, LLC, 2010.

[6] El Asmar, Mounir, Awad S. Hanna, and Wei-Yin Loh. "Evaluating Integrated Project Delivery Using the Project Quarterback Rating.” Journal of Construction Engineering and Management 142, no. 1 (January 2016): 04015046. doi:10.1061/(asce)co.19437862.0001015 
[7] Xue, Xiaolong, Qiping Shen, and Zhaomin Ren. "Critical Review of Collaborative Working in Construction Projects: Business Environment and Human Behaviors.” Journal of Management in Engineering 26, no. 4 (October 2010): 196-208. doi:10.1061/(asce)me.1943-5479.0000025.

[8] Mollaoglu-Korkmaz, Sinem, Lipika Swarup, and David Riley. "Delivering Sustainable, High-Performance Buildings: Influence of Project Delivery Methods on Integration and Project Outcomes.” Journal of Management in Engineering 29, no. 1 (January 2013): 71-78. doi:10.1061/(asce)me.1943-5479.0000114.

[9] Khanzadeh, M., Sh. Dabirian, H. Honesi Zadeh Matlabi. "Evaluation and ranking factors effective on time, cost and quality of mass housing building projects in Iran by using Analytical Hierarchy Process (AHP)". International Conference on Project Management: Tehran, Iran, (2007).

[10] Fish, Amanda. 2011. "Integrated Project Delivery: The Obstacles of Implementation.” MASTER OF SCIENCE Department of Architectural Engineering and Construction Science College of Engineering, B.S., Kansas State University, 2011 A, 1-52.

[11] Becerik-Gerber, B, DDes, and D. C. Kent. "Implementation of Integrated Project Delivery and Building Information Modeling on a Small Commercial Project.” International Journal of Project Management, (2010): 1-6.

[12] Guide, A. I. A. "Integrated project delivery: A guide." American Institute of Architects, California (2007).

[13] Erkessousi, N. El. "How Integrated Project Delivery is an Advantage to the Danish Building Industry, and how it can be executed." Unpublished Bachelor of Architectural Technology \& Construction Management Thesis (2010).

[14] Nejati, Iman, Mahyar Javidruzi, and Amir Hossein Mohebifar. "Feasibility of using an Integrated Project Delivery (IPD) in mass housing collaborative projects." Advances in Environmental Biology (2014): 211-219.

[15] Zhang, Lianying, and Fei Li. "Risk/Reward Compensation Model for Integrated Project Delivery.” Engineering Economics 25, no. 5 (December 18, 2014). doi:10.5755/j01.ee.25.5.3733.

[16] Kahvandi, Zahra, Ehsan Saghatforoush, Mohammad Mahoud, and Christopher Preece. "Analysis of the Barriers to the Implementation of Integrated Project Delivery (IPD): A Meta-Synthesis Approach." Journal of Engineering, Project, and Production Management 9, no. 1 (2019): 2-11. doi:10.2478/jeppm-2019-0002.

[17] Ilozor, Benedict D., and David J. Kelly. " Building Information Modeling and Integrated Project Delivery in the Commercial Construction Industry: A Conceptual Study.” Journal of Engineering, Project, and Production Management 2, no. 1 (January 31 , 2012): 23-36. doi:10.32738/jeppm.201201.0004.

[18] Kamaruddin, Siti Syariazulfa, Mohammad Fadhil Mohammad, and Rohana Mahbub. "Barriers and Impact of Mechanisation and Automation in Construction to Achieve Better Quality Products." Procedia - Social and Behavioral Sciences 222 (June 2016): 111-120. doi:10.1016/j.sbspro.2016.05.197.

[19] Molenaar, Keith, Nathaniel Sobin, D. Gransberg, T. McCuen, S. Korkmaz, and M. Horman. "Sustainable, high performance projects and project delivery methods: A state-of-practice report." White Paper for the Design-Build Institute of America and the Charles Pankow Foundation (2009).

[20] Autodesk, I. "Improving building industry results through integrated project delivery and building information modeling." (2008).

[21] Cohen, Johnathan. "Integrated project delivery: Case studies." AIA National, AIA California Council, AGC California and McGraw-Hill (2010).

[22] Collins, Wesley, and Kristen Parrish. "The Need for Integrated Project Delivery in the Public Sector." Construction Research Congress 2014 (May 13, 2014). doi:10.1061/9780784413517.074.

[23] Manning, Ryan T. "Challenges, Benefits, \& Risks Associated with Integrated Project Delivery and Building Information Modeling." (2012).

[24] Baiden, Bernard K., and Andrew D.F. Price. "The Effect of Integration on Project Delivery Team Effectiveness." International Journal of Project Management 29, no. 2 (February 2011): 129-136. doi:10.1016/j.ijproman.2010.01.016.

[25] The American Institute of Architects. "IPD Case Studies." School of Architecture Minnesota University. by the AIA / AIA California Council, no. March: (2012): 1-116.

[26] Ghassemi, Reza, and Burcin Becerik-Gerber. "Transitioning to Integrated Project Delivery: Potential barriers and lessons learned." Lean construction journal (2011).

[27] Kagioglou, Mike, and Patricia Tzortzopoulos, eds. "Improving Healthcare through Built Environment Infrastructure" (February 10, 2010). doi:10.1002/9781444319675. 
[28] Ahmad, Irtishad, Nida Azhar, and Arindam Chowdhury. "Enhancement of IPD Characteristics as Impelled by Information and Communication Technology." Journal of Management in Engineering 35, no. 1 (January 2019): 04018055. doi:10.1061/(asce)me.1943-5479.0000670.

[29] Kahvandi, Zahra, Ehsan Saghatforoush, Mahdi Alinezhad, and Christopher Preece. "Analysis of Research Trends on Benefits of Implementing Integrated Project Delivery (IPD)." In International Conference on Civil, Mechanical Engineering \& Construction Management (CMC 2016). 2016.

[30] Ma, Zhiliang, Dongdong Zhang, and Jiulin Li. "A Dedicated Collaboration Platform for Integrated Project Delivery." Automation in Construction 86 (February 2018): 199-209. doi:10.1016/j.autcon.2017.10.024.

[31] Kent, David C., and Burcin Becerik-Gerber. "Understanding Construction Industry Experience and Attitudes Toward Integrated Project Delivery." Journal of Construction Engineering and Management 136, no. 8 (August 2010): 815-825. doi:10.1061/(asce)co.1943-7862.0000188.

[32] Mesa, Harrison A., Keith R. Molenaar, and Luis F. Alarcón. "Exploring Performance of the Integrated Project Delivery Process on Complex Building Projects." International Journal of Project Management 34, no. 7 (October 2016): 1089-1101. doi:10.1016/j.ijproman.2016.05.007.

[33] Choi, Jiyong, Sungmin Yun, Fernanda Leite, and Stephen P. Mulva. "Team Integration and Owner Satisfaction: Comparing Integrated Project Delivery with Construction Management at Risk in Health Care Projects.” Journal of Management in Engineering 35, no. 1 (January 2019): 05018014. doi:10.1061/(asce)me.1943-5479.0000654.

[34] Kahvandi, Z, E Saghatforoush, A Zare Ravasan, and T Mansouri. "An FCM-Based Dynamic Modelling of Integrated Project Delivery Implementation Challenges in Construction Projects.” Lean Construction Journal 87: (2018): 63-87.

[35] Roy, Debopam, Sagar Malsane, and Pradeepta K. Samanta. "Identification of Critical Challenges for Adoption of Integrated Project Delivery." Lean Construction Journal (2018).

[36] Kahvandi, Zahra, Ehsan Saghatforoush, Mahdi Alinezhad, and Farimah Noghli. "Integrated Project Delivery (IPD) Research Trends." Journal of Engineering, Project, and Production Management 7, no. 2 (July 31, 2017): 99-114. doi:10.32738/jeppm.201707.0006.

[37] Ashcraft, Howard. "Integrated Project Delivery : Optimizing Project Performance." OwnersPerspective.Org, (2014): 16-21.

[38] Kelly, David, and B. Ilozor. "A pilot causal comparative study of project performance metrics: examining building information modeling and integrated project delivery." The Built \& Human Environment Review 6 (2013).

[39] El Asmar, Mounir, Awad S. Hanna, and Wei-Yin Loh. "Quantifying Performance for the Integrated Project Delivery System as Compared to Established Delivery Systems." Journal of Construction Engineering and Management 139, no. 11 (November 2013): 04013012. doi:10.1061/(asce)co.1943-7862.0000744.

[40] Fish, A, and Julia Keen. "Integrated Project Delivery: The Obstacles of Implementation." Manhattan: Master Dissertation, Kansas State University, (2011): 90-97.

[41] MacCallum, Robert C., Keith F. Widaman, Kristopher J. Preacher, and Sehee Hong. "Sample Size in Factor Analysis: The Role of Model Error.” Multivariate Behavioral Research 36, no. 4 (October 2001): 611-637. doi:10.1207/s15327906mbr3604_06.

[42] Reio, Thomas G., and Brad Shuck. "Exploratory Factor Analysis.” Advances in Developing Human Resources 17, no. 1 (November 28, 2014): 12-25. doi:10.1177/1523422314559804.

[43] Treiblmaier, Horst, and Peter Filzmoser. "Exploratory Factor Analysis Revisited: How Robust Methods Support the Detection of Hidden Multivariate Data Structures in IS Research.” Information \& Management 47, no. 4 (May 2010): 197-207. doi:10.1016/j.im.2010.02.002.

[44] Chin, Wynne W., Abhijit Gopal, and W. David Salisbury. "Advancing the Theory of Adaptive Structuration: The Development of a Scale to Measure Faithfulness of Appropriation.” Information Systems Research 8, no. 4 (December 1997): $342-367$. doi:10.1287/isre.8.4.342.

[45] Pishdad-Bozorgi, Pardis, and Yvan J. Beliveau. "Symbiotic Relationships between Integrated Project Delivery (IPD) and Trust." International Journal of Construction Education and Research 12, no. 3 (February 19, 2016): $179-192$. doi:10.1080/15578771.2015.1118170.

[46] Abdirad, Hamid, and Pardis Pishdad-Bozorgi. "Trends of Assessing BIM Implementation in Construction Research." Computing in Civil and Building Engineering (2014) (June 17, 2014). doi:10.1061/9780784413616.062.

[47] Bilbo, David, Ben Bigelow, Edelmiro Escamilla, and Christa Lockwood. "Comparison of Construction Manager at Risk and Integrated Project Delivery Performance on Healthcare Projects: A Comparative Case Study." International Journal of Construction Education and Research 11, no. 1 (April 3, 2014): 40-53. doi:10.1080/15578771.2013.872734. 
[48] Monteiro, André, Pedro Mêda, and João Poças Martins. "Framework for the Coordinated Application of Two Different Integrated Project Delivery Platforms.” Automation in Construction 38 (March 2014): 87-99. doi:10.1016/j.autcon.2013.11.003.

[49] Birnleitner, Helmut, and Doctorate Student. "Influence of macro-environmental factors to the process of integrating a foreign business entity." In Proceedings from Industry, science and policy makers for sustainable future: the 14th Management International Conference, pp. 21-23. 2013. 


\section{Appendix I: The questionnaire items}

A questionnaire to determine the barriers affecting the implementation of modern systems in construction contracts.

The current questionnaire is designed and evaluated to examine the effective barriers to the implementation of modern systems in construction contracts. Given that you have the experience of participating in the consultation or implementation of the construction project implementation system, please comment on the questions posed in this questionnaire.

What is your gender?

$\square$ Male $\square$ Female

How old are you?

\section{$\square 18-25 \square 26-35 \square 36-45 \square 46-55 \square 56-65 \square 66-75 \square$ Older than 75}

What is the highest level of education you have completed?

$\square$ High school graduate $\square$ Two-year/associate's degree or some college $\square$ Four-year or bachelor's degree $\square$ Graduate or master’s degree $\square$ Professional degree (for example, MD, JD, DDS) $\square$ Postgraduate degree or $\mathrm{PhD}$

Please highlight the importance of the obstacles listed in the following table in implementing the new project implementation systems, such as integrated project delivery, by choosing an option (from 1 (strongly low) to 9 (strongly high)).

\begin{tabular}{|c|c|c|c|c|c|c|c|c|c|}
\hline Items & 1 & 2 & 3 & 4 & 5 & 6 & 7 & 8 & 9 \\
\hline 1. Lack of proper definition of teamwork culture among project key stakeholders & $\square$ & $\square$ & $\square$ & $\square$ & $\square$ & $\square$ & $\square$ & $\square$ & $\square$ \\
\hline $\begin{array}{l}\text { 2. Lack of integrated collaboration among key stakeholders, due to lack of the } \\
\text { necessary technology }\end{array}$ & $\square$ & $\square$ & $\square$ & $\square$ & $\square$ & $\square$ & $\square$ & $\square$ & $\square$ \\
\hline $\begin{array}{l}\text { 3. Non-participation of governmental agencies in construction, according to the } \\
\text { governing rules in the governmental contracts }\end{array}$ & $\square$ & $\square$ & $\square$ & $\square$ & $\square$ & $\square$ & $\square$ & $\square$ & $\square$ \\
\hline 4. The challenge of selecting compensator for financial losses & $\square$ & $\square$ & $\square$ & $\square$ & $\square$ & $\square$ & $\square$ & $\square$ & $\square$ \\
\hline 5. Change in accounting scheme of key stakeholders & $\square$ & $\square$ & $\square$ & $\square$ & $\square$ & $\square$ & $\square$ & $\square$ & $\square$ \\
\hline 6. Disappointment to choice the suitable construction team & $\square$ & $\square$ & $\square$ & $\square$ & $\square$ & $\square$ & $\square$ & $\square$ & $\square$ \\
\hline 7. Lack of passable knowledge of people to solve the difficulties & $\square$ & $\square$ & $\square$ & $\square$ & $\square$ & $\square$ & $\square$ & $\square$ & $\square$ \\
\hline 8. Unclear duty of each of parties & $\square$ & $\square$ & $\square$ & $\square$ & $\square$ & $\square$ & $\square$ & $\square$ & $\square$ \\
\hline 9. Lack of using BIM as an appropriate instrument to implement IPD approach & $\square$ & $\square$ & $\square$ & $\square$ & $\square$ & $\square$ & $\square$ & $\square$ & $\square$ \\
\hline $\begin{array}{l}\text { 10. Lack of sufficient knowledge about design and construction and maintenance } \\
\text { among employer agents }\end{array}$ & $\square$ & $\square$ & $\square$ & $\square$ & $\square$ & $\square$ & $\square$ & $\square$ & $\square$ \\
\hline $\begin{array}{l}\text { 11. Lack of holding training courses for investors about defining and stating the } \\
\text { advantages of new successful contractual systems all over the world }\end{array}$ & $\square$ & $\square$ & $\square$ & $\square$ & $\square$ & $\square$ & $\square$ & $\square$ & $\square$ \\
\hline 12. Poor information sharing among different phases of the project & $\square$ & $\square$ & $\square$ & $\square$ & $\square$ & $\square$ & $\square$ & $\square$ & $\square$ \\
\hline 13. Lack of existence of like IPD contracts & $\square$ & $\square$ & $\square$ & $\square$ & $\square$ & $\square$ & $\square$ & $\square$ & $\square$ \\
\hline $\begin{array}{l}\text { 14. Lack of mutual trust among project key stakeholders regarding managerial and } \\
\text { financial issues }\end{array}$ & $\square$ & $\square$ & $\square$ & $\square$ & $\square$ & $\square$ & $\square$ & $\square$ & $\square$ \\
\hline 15. Retaining the right of ending decision for the owner & $\square$ & $\square$ & $\square$ & $\square$ & $\square$ & $\square$ & $\square$ & $\square$ & $\square$ \\
\hline $\begin{array}{l}\text { 16. Lack of conditions for the insurance to cover the entire project in the country, } \\
\text { according to new contractual systems }\end{array}$ & $\square$ & $\square$ & $\square$ & $\square$ & $\square$ & $\square$ & $\square$ & $\square$ & $\square$ \\
\hline $\begin{array}{l}\text { 17. Lack of conditions for the insurance to cover the responsibilities according to new } \\
\text { contractual systems for the contractor }\end{array}$ & $\square$ & $\square$ & $\square$ & $\square$ & $\square$ & $\square$ & $\square$ & $\square$ & $\square$ \\
\hline 18. No program for payment & $\square$ & $\square$ & $\square$ & $\square$ & $\square$ & $\square$ & $\square$ & $\square$ & $\square$ \\
\hline 19. Lack of direction in payment systems & $\square$ & $\square$ & $\square$ & $\square$ & $\square$ & $\square$ & $\square$ & $\square$ & $\square$ \\
\hline 20. Poor matrix structure in project-based organizations & $\square$ & $\square$ & $\square$ & $\square$ & $\square$ & $\square$ & $\square$ & $\square$ & $\square$ \\
\hline $\begin{array}{l}\text { 21. Lack of sufficient knowledge of investors about new successful contractual } \\
\text { systems all over the world }\end{array}$ & $\square$ & $\square$ & $\square$ & $\square$ & $\square$ & $\square$ & $\square$ & $\square$ & $\square$ \\
\hline 22. Failure to select the suitable design team & $\square$ & $\square$ & $\square$ & $\square$ & $\square$ & $\square$ & $\square$ & $\square$ & $\square$ \\
\hline 23. Lack of direction in managing project organization & $\square$ & $\square$ & $\square$ & $\square$ & $\square$ & $\square$ & $\square$ & $\square$ & $\square$ \\
\hline 24. Lack of identical contracts among subcontractors, such as IPD approach & $\square$ & $\square$ & $\square$ & $\square$ & $\square$ & $\square$ & $\square$ & $\square$ & $\square$ \\
\hline
\end{tabular}




\begin{tabular}{|l|l|l|l|l|l|l|l|l|l|}
\hline 25. Tendency to use conventional contractual methods and resistance to new ideas & $\square$ & $\square$ & $\square$ & $\square$ & $\square$ & $\square$ & $\square$ & $\square$ \\
\hline 26. Lack of proper definition of responsibilities of each of parties of the contract & $\square$ & $\square$ & $\square$ & $\square$ & $\square$ & $\square$ & $\square$ & $\square$ \\
\hline 27. Lack of existence of preparation materials in country & $\square$ & $\square$ & $\square$ & $\square$ & $\square$ & $\square$ & $\square$ & $\square$ \\
\hline 28. Lack of integrated interoperability because of lack of essential technology & $\square$ & $\square$ & $\square$ & $\square$ & $\square$ & $\square$ & $\square$ & $\square$ \\
\hline 29. Inconsistency in project management & $\square$ & $\square$ & $\square$ & $\square$ & $\square$ & $\square$ & $\square$ & $\square$ \\
\hline 30. Lack of existence of right stakeholders in a place through all phases of the project & $\square$ & $\square$ & $\square$ & $\square$ & $\square$ & $\square$ & $\square$ & $\square$ \\
\hline 31. Changes in the original design in the construction phase & $\square$ & $\square$ & $\square$ & $\square$ & $\square$ & $\square$ & $\square$ & $\square$ \\
\hline 32. Corporations get used to traditional systems & $\square$ & $\square$ & $\square$ & $\square$ & $\square$ & $\square$ & $\square$ & $\square$ \\
\hline 33. Disinclination of stakeholders to contribute in a project with common benefits & $\square$ & $\square$ & $\square$ & $\square$ & $\square$ & $\square$ & $\square$ & $\square$ \\
\hline 34. Opposition of stakeholders to take risk & $\square$ & $\square$ & $\square$ & $\square$ & $\square$ & $\square$ & $\square$ & $\square$ \\
\hline 35. Lack of appropriate policies and current construction contractual strategies & $\square$ & $\square$ & $\square$ & $\square$ & $\square$ & $\square$ & $\square$ & $\square$ \\
\hline 36. Contracts that make several units to follow it & $\square$ & $\square$ & $\square$ & $\square$ & $\square$ & $\square$ & $\square$ & $\square$ \\
\hline 37. Lack of control and strong management of the employer & $\square$ & $\square$ & $\square$ & $\square$ & $\square$ & $\square$ & $\square$ & $\square$ \\
\hline 38. Lack of existence of appropriate conditions for IPD implementation in the public & $\square$ & $\square$ & $\square$ & $\square$ & $\square$ & $\square$ & $\square$ & $\square$ \\
\hline Construction part & $\square$ \\
\hline 39. Lack of proper orientation for future and not paying attention to future \\
development, particularly in the governmental projects & $\square$ & $\square$ & $\square$ & $\square$ & $\square$ & $\square$ & $\square$ & $\square$ \\
\hline 40. Lack of familiarity of contractors with IPD approach & $\square$ & $\square$ & $\square$ & $\square$ & $\square$ & $\square$ & $\square$ & $\square$ \\
\hline 41. Underestimation of the ending cost & $\square$ & $\square$ & $\square$ & $\square$ & $\square$ & $\square$ & $\square$ & $\square$ \\
\hline 42. Lack of transparency in costs & $\square$ & $\square$ & $\square$ & $\square$ & $\square$ & $\square$ & $\square$ & $\square$ \\
\hline 43. Specific supplies of insurance to the full project & $\square$ & $\square$ & $\square$ & $\square$ & $\square$ & $\square$ & $\square$ & $\square$ \\
\hline 44. Lack of motivation for investors to use modern contracts, such as IPD approach & $\square$ & $\square$ & $\square$ & $\square$ & $\square$ & $\square$ & $\square$ & $\square$ \\
\hline
\end{tabular}

